\title{
Building Online Learning Community for Higher Education
}

\author{
Yang Libo, Ouyang Fuyao \\ Computer and Information Technology College, \\ Northeast Petroleum University \\ Daqing 163318, Heilongjiang, China \\ springsense@163.com
}

\begin{abstract}
Online learning community is a virtual community composed of people who aim at achieving shared learning objectives through social networking and computer-mediated communication. By introducing roles of online learning communities and discussing the issues of building or developing an online learning community with the case of curriculum of Director of Television and Film, the author proposes that online learning community provides an effective platform for university students to learn.
\end{abstract}

\section{Keywords-learning community; design; learning abilities}

\section{INTRODUCTION}

The emergence of learning community is an interesting and recent pedagogical development in higher education. A learning community is one of the ways that individuals perceive community in the higher education setting. Online networking is a valuable tool for students in higher education and in the world of work [1].

Online learning community (OLC) is well supported by learning theories that emphasize the role of social interaction in the construction of knowledge. Online learning community advocates the collaborative means of achieving "shared creation" and "shared understanding". Community members are encouraged to support individual and collective learning. Online learning community provides university students with many opportunities for flexible, informal learning.

\section{DEFINITION OF ONLINE LEARNING COMMUNITY}

During past 20 years, the term "learning community" has come to be widely used in education. The concept of community is multifaceted. At present, the term "learning community" lacks a uniform definition. When applied to an online environment, the concept becomes even more complex.

It is necessary to define "community" before defining "learning community". What is a community? Community is a common concept in the social sciences and humanities. Lave and Wenger introduced the concept of Community of Practice to convey the emerging process of social learning as a group of people work cooperatively [2]. Wenger defined "communities of practice" as "groups of people who share a concern or passion for something they do and who interact regularly to learn how to do it better" [3].Brook and Oliver defined community as "a sense that members have a belonging, members matter to one another and to the group and a shared faith that member's needs will be met through their commitment to be together" [4].

Lieberman and Wenger defined the learning community as a commonplace where people interact, learn, and collaborate through group activities which foster them how to define problems, decide upon a resolution, and achieve the solution [5]. Gabelnick defined "learning communities, as we define them, purposefully restructure the curriculum to link together course or course work so that students find greater coherence in what they are learning as well as increased intellectual interaction with faculty and fellow students" [6]. In his view, learning community is usually associated with collaborative and active approaches to learning, some form of team teaching, and interdisciplinary themes. His definition guides learning community at many institutions with the importance of curricular restructuring, integration of material and interaction of students and teachers.

With the development of distance education, ICT researchers have begun turning their attention to the significance of online community in learning and teaching. Up to date, there is no generally accepted definition of online community. The term means different things to different people. The work of Howard Rheingold is a good starting point for any sociological investigation of online communities. He says that virtual communities are cultural aggregations that emerge when enough people bump into each other often enough in cyberspace [7]. He goes to say that a virtual community as they exist today is a group of people who may or may not meet one another face to face, and who exchange words and ideas through the mediation of computer bulletin boards and networks.

\section{ROLES OF ONLINE LEARNING COMMUNITY}

Online learning community is the equivalent to learning organization. The main role of an online learning community includes learners, facilitators and experts. Thus, people in the community can perform their own duties to ensure the development of the community.

\section{A. Learners}

Learners are the main participants in the learning activities, as well as in the online environment. All of learning activities should be designed based the principle of learner-centered. In the activities, learners create their own product and communicate with others in order to promote the individual continuous development. Learners are also the 
constructors of self-learning abilities. Learning community is developed guided by constructivist theory, which emphasizes individual learners should continue to integrate the surrounding resources to promote their own development. The promotion of learning abilities and construction of knowledge should rely on the effort of learners themselves.

\section{B. Facilators}

Facilitators in online learning community mainly refer to the instructors who design the teaching activities. Facilitators are the founders of the shared vision of online learning community. In online learning community, facilitators ought to formulate the shared vision according to the learning objectives and characters of learners. Shared vision should pay attention to learners' development, progress, etc. In the whole process of learning, facilitators will answer questions in a timely manner and correct the wrongness directing at the problems that learners put forward to make them complete their learning tasks. The facilitator needs to pay careful attention to welcoming each student to the electronic course, and reinforcing early attempts to communicate [8].

\section{Experts}

Experts are another important role in online learning community. Although experts are also belonging to the range of facilitators, there is the deference between facilitators and experts. The different is that experts are also the instructors, inspirers, helpers of the learning activities. As professional instructors, experts need help learners solve their problems about the course to facilitate learners to complete the learning task successfully. They will provide facilitators with instruction strategies. According to the feedbacks of facilitators, experts will assist them to design the teaching again in order to solve the problems emerged in the learning activities.

In online learning community, the relationship between learners, facilitators and experts are inseparable. Learners are the main body of learning activities. The shared vision and learning contents must be designed according to the development of them. As guiders of learning activities, facilitators formulate the learning objectives and shared vision for learners according to the teaching contents and the learners' analysis. Experts provide learners and facilitators with solutions to the problems to promote the development of learning communities. The relationship between the three roles can be represented as Figure 1.

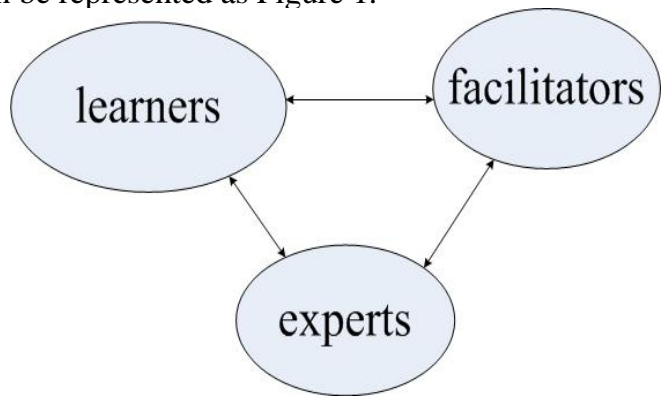

Figure 1. Relationship between roles of OLC
As shown in Figure 1, in an online learning community, learners, facilitators and experts are independent. However, there also exists interaction between them. The continuous development of learners, facilitators and experts promote the progress of online learning community. The improvement of learning community also benefits individual development of learners and facilitators as well as the experts.

\section{A CASE ANALYSIS OF BUILDING AN ONLINE LEARNING COMMUNITY}

\section{A. Strategies of Building Online Learning Community}

- Establish common goals. The common learning goal is the foundation of developing and supporting online learning communities. Online learning community reflects the opinion of constructivism learning theory, namely that learning is not passively absorption and accumulation of information. Learners should construct their own knowledge rather than accepting that given by instructors. The main purpose of building this online learning community is to facilitate students majoring in educational technology to learn the professional course of Director of Television and Film, to promote them to grasp various kinds of shooting skills and to share learning experience as well.

- Design the learning resources. Online learning community should provide opportunities for their members at anytime, anywhere to achieve learning resources. Having identified the goals, instructors need to design and develop corresponding learning resources. Learning resources include media resources, web resources, electronic materials and etc.

- Identify the role of members. As the equivalent to a learning organization; our online learning community includes instructors, moderators and individual learners. Instructors, as the organizers and leaders of discussions will present with curriculumrelated topics and define the environment. Instructors will keep discussions to go on and ensure discussions off track. They also need to pay careful attention to welcoming each student to the online learning community and enhancing early attempts to communicate with them. More importantly, instructors can offer advice to learners, and provide more help and support for them with the effect of building up learners' confidence, attitudes, selfconfidence, together with enhancing the sense of participation [9].

- Make guidelines and rules. The guidelines and rules is the basic code of conduct of the individuals in the online learning community. Appropriate rules are needed for the online learning community when starting to build it, such as registration policies, membership obligations, codes of behaviors for moderators. In our OLC, students are forbidden to talk about the topic unrelated to production of 
television and film and making vile remarks by other members of the community. Students also need to pay careful attention to the reply given by instructors. In a successful learning community, guidelines and rules governing the use of collective resources are well matched to the local needs and conditions.

\section{B. Process of Building Online Learning Community}

The process of building an online learning community is based on the course of Director of Television and Film. "Director of Television and Film" is the professional compulsory course of Department of Educational Technology in Northeast Petroleum University. It aims to develop learner's ability of production of television program. Through learning this curriculum, students are able to understand the basic theories and methods of production of television, master video editing technology including artistic photography, TV lighting, recording and storage of video, TV stunt, the control of the audio and voice, writing of text script, storyboard script etc. For the good teaching results, we established an online learning community-OLC for Director of Television and Film by using social software, aiming at promoting students' understanding of this course through the communication and interaction between members.

At first, only a few members spoke in the community and the topic they talked about was casual and unrelated to the curriculum. The enthusiasm of students involved in the discussion was not high. At the same time, deepen discussions about some problem didn't appear as expected. The phenomenon was mainly caused by the fact that students just started learning the curriculum. Students just studied the basic theories of television, such as history of television, the character of video camera which is easy understood. However, with the increase of members and learning indepth, the knowledge and skills that they were learning become more complex and difficult to be understood, some students began to discuss some problems such as composition, lighting and other knowledge in the learning community. But there were a few feedbacks in this time.

In order to encourage more students to participate in the discussion in the online learning community, instructors decided to conduct discussions and appoint one student as the moderator to organize members together. For example, they talked about experimental class and discussed the shooting skills of movement of the lens when many students didn't fully understand the content of the experiment. In view of this situation, the moderator put forward the common topic for discussion: how to shoot better move lens? In the discussion, with the guidance of moderator, students reviewed the concept of pushing, pulling, shaking, moving of shot as well as the appropriate composition and specific methods of operation. This benefited those members who still didn't clearly understand the knowledge. Next, the moderator would allow students to ask questions when they couldn't understand. Communication in the online learning community is shown in Figure 2 [10].

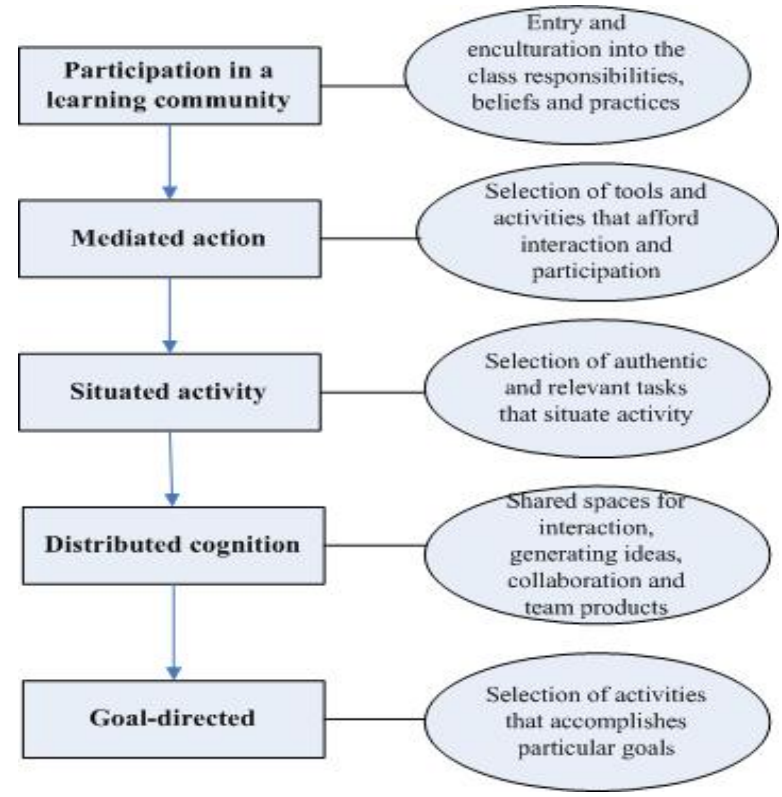

Figure 2. Communications of OLC

\section{Measures of improving motivation of learners}

Even though the moderator encouraged students to actively participate in discussions, several students weren't still active and weren't good at communicating with others. They remained silent and seldom or even never spoke in the learning community. Active students were always those ones. How to mobilize the enthusiasm of passive students and encourage them to participate in discussion is the key to a successful online learning community.

Therefore, we had to take measures to improve motivation of learners.

- Provide more topics for discussion. Occasionally, the topic of conversation can stimulate some people, but other members are not interested in it. Such result is usually that only a few members take part in the conversation and others keep silent. If we want to mobilize more students to participate in the discussion, more topics about the curriculum are indispensable.

- Provide links to sources of pertinent information. One of the advantages of online learning community is that it allows students to share a variety of learning resources in the network. If somebody finds good learning resources correspondent with the production of television and film, he can upload resources in our learning community so that other members can use these rich resources [11].

- Enhance the "sense of community" of learners. We ought to make all of members feel that they are in a united organization, individual behavior will affect the interests of the organization, and all people need to do is to actively participate in this learning community. 
Through common efforts of the members, the learning community becomes strong and formal. With deep learning of the course, most members can actively take part in these discussions. When a member express his or her doubt about some question in the learning, other members who are online will discuss the question together and offer corresponding answers in the end. It is recommended that instructors use online discussions because the discussion is an effective way to promote students to communicate with others in the community. In the process of learning, students felt safe and protected. They were free to communicate and felt encouraged by their group members. Through the communications in the online learning community, all of members felt that they improved problem-solving skills. In addition, the relationship between them become intimate.

\section{CONCLUSION}

The paper is shown that students can use online learning community to enhance their learning. Members regard the community as an opportunity to share ideas. Online learning community seems to lower the feeling of isolation some students feel. Online learning community provides members with the opportunity to interact with others. Members often benefit from personal support. An instructor's task is to identify students' individual needs, perhaps through a timely audit of skills and attitudes, and then to make sure that students have access to personal support from other students as well as from instructors or experts.

The online learning community implemented in this paper has been applied in Director of Television and Film in Northeast Petroleum University. The teaching effect is pretty good. By learning together in an online learning community, students have the chance to extend and deepen their understanding of this course, generate new ideas and achieve the knowledge such as: light types, lighting design methods, light adjusting, shooting techniques and shooting views, etc.

\section{REFERENCES}

[1] E.lisabeth Skinner, J. Derounian, "Building Community Through Online Discussion”, Learning and Teaching in Higher Education,vol. 8, pp. 57-70, 2007.

[2] E .Wenger, "Communities of practice: a brief introduction”, http:www.ewenger.com/theory/index.htm.

[3] R.Bacheleti, "Building a wider learning community in higher education through the PeopleWiki approach," http://rb.eclille.fr/perso/papers/Building_a_learning_Community_RemiBachelet_2008.pdf.

[4] C.Brook, R. Oliver, "Exploring Online Learning Community Development: The Relative Importance Of Influencing Factors",Proceedings of the 20th Annual Conference of the Australasian Society for Computers in Learning in Tertiary Education, pp. 63-73, 2003.

[5] M.H. Liu. "Integrating an Online Learning Community into Nonmajor Freshman English Instruction”, College English: Issues and Trends, vol. 2, pp. 128-154, 2008.

[6] F. Gabelnick, J. MacGregor, R. Matthews, , B. Smith, "Learning Communities: Creating Connections among Students", New Directions for Teaching and Learning,vol. 1990, pp. 5-18,1990.

[7] H.Rheingold, "A Slice of Life in My Virtual Community", http://public.clunet.edu/ chenxi/Phil350_142_03.pdf.

[8] C. J. Clark. "Let Your Online Learning Community Grow: 3 Design Principles for Growing Successful Email Listservs and Online Forums in Educational Settings", http://www.noendpress.com/caleb/olc/3Principles_Online_Comm.pdf.

[9] M. Andrew. "Strategically maintaining online learning community in a postgraduate writing program”, http://www.ascilite.org.au/conferences/sydney10/procs/Andrewfull.pdf.

[10] K. Elaine, C. Bronwen, "A Framework for Developing and Implementing an Online Learning Community”, Journal of Open, Flexible, and Distance Learning, vol. 15, pp. 47-59,2011.

[11] B. A. Pederson. "Building An Online Learning Community: A Major Communication Component Of The Virtual Assistant Certificate", https://www.uleth.ca/dspace/bitstream/handle/10133/1166/Pederson_ Beverly_A.pdf?sequence=1. 